\title{
A PAISAGEM POSSÍVEL
}

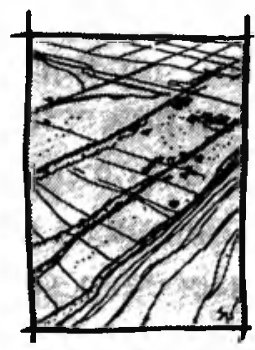

\section{PAULO RENATO MESQUITA PELLEGRINO}

A questão que vem latente por trás da linha de investigação que estamos envolvidos, da qual resultou a minha dissertação de mestrado, se confunde com a própria questão ambiental, ou seja, com a forma de relacionamento que a sociedade tem com as bases naturais que lhe são 0 suporte de sua própria sobrevivência. $O$ problema de verificação de determinados fatos, e de sua continuidade, apesar da irracionalidade que apresentam face a uma ótica conservacionista, continua sem uma racionalização mais convincente, apesar do maior aprofundamento alcançado quanto às formas deste relacionamento.

Todo o processo de conhecimento, levado na execução da dissertação de mestrado, se pautou pelo objetivo de se alcançar um controle de variáveis mais amplas, necessárias parao projeto doespaço da vida, ou seja: a partirde um planejamentoecológicointegral, propor sínteses criativas, através de uma operacionalização viabilizada pela figura da paisagem. Para tanto, iniciou-se com a busca de um quadro de referência teórico, com a conceituação de totalidade a partir de Kosik, e da Teoria Geral dos Sistemas, especialmente em sua tradução espacializada nos sistemas ecológicos, permitindo a hipótese da intervenção deliberada visando a evolução desses sistemas, como propõe Berry. Para o processo de conhecimento da realidade em si, definido o espaço de aplicação, que passou por um contínuo processo de ampliação até abarcar o sistema urbano que tem em seus vértices São Paulo, Campinas e Sorocaba, e seus espaços intersticiais; passamos à sua análise, ou um inventário paisagístico, dividindo os subsistemas natural e antrópico em seus componentes relevantes para a identificação das especificidades espaciais, enquanto condicionantes, como restrições e potencialidades, àstensões impostas pelas ações humanas; comoas próprias rugosidades, que influenciam e ajudam a conformar as intervenções operadas.

Os subsistemas antrópicos foram analisados por um viés temporal, por intermédio de uma periodização, que se mostrou fundamental na compreensão do atual estado das coisas, ao revelar a sua gênese. Com a integração de toda a informação levantada, numa síntese paisagística, com a definição de Unidades de Paisagem, foi elaborado um esquema conceitual que expressa uma desejável ocupação do espaço, tendo-se em vista os objetivos de conservação dos recursos, entendidos como a totalidade dos fatores suportes da vida; de um real processo de desenvolvimento auto-sustentado, e por fim, da evolução do meio ambiente para estágios superiores de percepção ambiental, seja a nível do conforto como da estética. 
Todo este encadeamento lógico partia do pressuposto de que estes estágios superiores de percepção ambiental, fossem possíveis de ser interpretados por todos os usuários do ambiente em questão, pois seria a partir destes valores estabelecidos que se poderia montar uma estratégia de compreensão, antecipação, desvio e introdução gradual dos eventos evolucionários de acordo com as metas, a partir da mudança de hábitos dos próprios agentes responsáveis pelas transformações espaciais. Mas ocorre que aqui resvalamos no imponderável, ou seja, na impossibilidade de estabelecer um processo de percepção ambiental único, com uma gama tão varíivel e heterogênea, como o universo humano em questão, com lodas as suas imbricações sócioeconômicas e culturais; além de ser questionável que a nossa percepção individual possa ter um peso representativo, neste confronto com as percepções coletivas. Pois, afinal, se a imensa maioria das ações de transformações levadas a efeito sobre o território, tendem a fortalecer uma postura contrária aos objetivos, que por bem resolvemos entender como interessantes ao processo de cvolução ambiental, não seria, portanto, com o estabelecimento do mais "correto" que os fatos tenderiam a se moldar a nossa interpretação. Na dialética do real, no âmbilo de efetivação das coisas. o "racional" tende a estar muito matizado, como a resultante de uma somatória de forças, contra a qual, o mais lógico dos discursos pouco pode fazer.

Nesta retomada de contas com o real é que lançamos a tese de que a produção de paisagem poderá ser melhor compreendida pelo viés da percepção ambiental, a partir da consideração de que somos capazes apenas de ver aquilo que conseguimos interpretar; e de que nossas ações, nosso comportamento, é moldado pela nossa interpretação da paisagem. Deste modo esperamos avançar um pouco mais no entendimento desia conflituosa relação da sociedade com a natureza.

\section{DEFININDO A PROBLEMÁTICA}

As idéias envolvidas neste trabalho concernem principalmente com a interpretação da paisagem e com a nossa experiência, numa tentativa de explicar o fenômeno dos nossos entomos visíveis: como se originaram e desenvolveram, como se relacionam entre si, como diferem individualmente e em associação um com o oulro, de lugar para lugar.

A interação entre o indivíduo e seu ambiente, através da experiência, estabelece um conlato de duplo sentido entre o sujeito interpretante e o signo objeto de interprelação, a paisagem, com uma geração de significados, caracterizando um processo de percepção ambiental. Esta atribuição de significados, num procedimento semântico, passa por um filtro ideológico, como é colocado por Thomas: "loda a observação do mundo da nalureza envolve a utilização de categorias mentais com que nós, os observadores, classificamos e ordenamos a massa de fenômenos ao nosso redor. a qual 
de outra forma permaneceria incompreensível,eé sabidoque, uma vezaprendidas essas categorias, passa a ser bastante difícil ver o mundo de outra maneira. $O$ sistema de classificação dominante toma posse de nós, moldando nossa percepção e, desse modo nosso comportamento". E como complementa Appleton, o comportamento é de fato influenciado pela atitude de um indivíduo em relação ao ambiente, não como ele é, mas como ele pensa que seja; sendo que esta influência se opera por estágios.

Esta fixação das crenças, pela normatização dos juízos estabelecidos, é a sedimentação dos hábitos, ou seja, das formas de ação dos homens na natureza e entre si, dando uma possível explicação do porque da ocorrência dos problemas ambientais, Portanto, com a consideração. como demonstrada por Meinig, de que qualquer paisagem é composta não apenas pelo que se estende defronte aos nossos olhos, mas pelo que se encontra dentro de nossas mentes, é que as raízes da tão aparente degradação ambiental devem ser procuradas; enfim, as suas causas primeiras estariam nas formas em que as pessoạs se organizam em padrões de poder, produção e ideologia, em presença do que nós convencionalmente chamamos natureza.

A compreensão dos problemas ambientais como produto das interações sociedade/ natureza, explicados pelo modo de pensare se comportar pelos membros da sociedade, definidos a partir de regras estabelecidas pelo processo perceptivo, abre a possibilidade de uma visão evolucionista, como uma continuidade entre o possível e o real, na qual a geração de idéias a partir de outras, gera também uma atitude desatomatizante em relação aos hábitos estabelecidos, como o resultado da influência das novas informações adquiridas.

Estas consideraçōes nos levam a admitir que ao trabalharmos com a paisagem enquanto uma atividade de linguagem, seja numa análise interpretativa, seja em sínteses prospectivas em planos ou projetos, o que em realidade estamos trabalhando não é simplesmente com uma situação ecológica, mas com uma idéia de natureza socialmente construída, que responde por determinadas crenças normatizadas. Os objetivos da atividade projetual na paisagem, passam a ser, então, o de como fazer estes padrões sócioecológicos funcionarem melhor, pelo estabelecimento de uma ocupaçãoduradoura de determinados ambientes, com o descobrimento das demandas adequadas e do seu ajuste à capacidade de suporte dos ecossistemas. Isto ludo, entendido através da dinâmica e dialética interação entre os seres humanos (no contexto de suas sociedades e modos de produção) c esta mesma naturcza, como um processo historicamente emergente, em que a posição do homem no esquema geral das coisas seja melhor compreendida.

Todo este trato prálico-utilitário do projeto de paisagem envolve uma negociação sócioecológica com as realidades materiais e ideológicas em que vivemos, por meio dos 
parâmetros dados por um estado normativo da natureza, sendo convencionada a natureza intocada como referencial contra o qual as condições de um ambiente são medidas. Do que é tirada a afirmação de que os problemas ambientais significam o resultado de uma visão reducionista, que não leva adequadamente em consideração a totalidade da natureza.

Mas a própria operacionalidade funcional das representações, em discurso ou projeto, sofrem da inerente condição de signos de uma linguagem: são uma representação forçosamente parcial do objeto representado, pois a própria interpretação significante advém de um trabalho de seleção das variáveis representantes. Isto demonstra a impossibilidade de conhecimento da totalidade do objeto.

Esta característica da atividade perceptiva, de se processar pelas partes para a apreensão, pelas suas relações com o todo, do significado do objeto em seu contexto, estabelece a possibilidade de representações parciais apenas. Estando a complexidade do real passível de ser vislumbrada apenas por uma percepção integrada de todos os sentidos, engajados numa experiência direta, ou seja, numa ação sobre a natureza, de tal forma que tanto esta como o agente, já não serão os mesmos de um momento para o outro. Isto se dá principalmente em se tratando de paisagens, pois, desde que existem uma infinita variedade de condições ambientais, há também a possibilidade para a experiência do entomo visível assumir inumeráveis formas, como uma contínua ampliação de um processo de conhecimento para o indivíduo envolvido nesta interação como o seu ambiente.

A ciência da ecologia é suposta de oferecer uma das mais acuradas representações da natureza, permitindo que o contexto e as relações sejam levadas em consideração ao se projetar, ao se distribuir os usos no espaço; mas apesar de que a ecologia possa nos prover com um conhecimento importante no trato com os problemas ambientais, não podemos presumirquea ecologia sozinha nos forneça uma representação suficiente que nos possibilite acomodar nossas atividades sociais aos condicionantes da natureza, pois tanto a totalidade de uma como a de outra não é mais acessível para nós que as suas partes, e as próprias leis da ecologia não são mais que um particular conjunto de experiênciase interpretações socialmente construídas, com todasas implicaçõese bases políticas e morais, ideológicas enfim, que advêm deste fato, e que portanto é questionável em sua verdade objetiva.

A percepção dos problemas ambientais se dá através de uma grande variedade de interesses: de saúde, de sobrevivência, de aspectos morais, de empatia, estéticos, políticos, econômicos, culturais, etc. Estes interesses amalgamados pela experiência individual, coletiva, histórica, Iranscultural e visionária são socialmente estabelecidos (negociados através do tempo) e socialmente interpretados (alravés de processos associativos 
que estabelecem juizos perceptivos), e esta historicidade lhes dá um enorme peso normativo.

As escolhas que fazemos sobre experiências significativas e princípios morais aceitos, ou seja, em juízos perceptivos, é que estão na origem dos problemas ambientais, que não são, portanto, resultados de uma compreensĩo errada da nalureza, mas numa interpretação possível da natureza; que pode ser vista como uma negociação fallha com e na construção da natureza, na configuração de novas ordenações sócioecológicas de realidade, o que reflete práticas sociais falhas, pois alguns segmentos da sociedade se engajam em práticas que afetam adversamente outros membros da sociedade, com o potencial de prejudicar a futura qualidade e habitabilidade do planeta. Estes problemas surgem freqüentemente da falta de participação democrática nas escolhas que podem afetar drasticamente nossas vidas, como resultado de relação com a natureza e entre as pessoas que podem ser considerados aéticos.

Como conclusão poderiamos inferir que a resolução e prevenção dos problemas ambientais não estão no conhecimento suticiente da natureza, mas em como nós negociamos e interagimos com as especificidades ambientais, e de que necessitamos do estabelecimento de princípios sociais que normatizem interações apropriadas com a natureza. Mas quais seriam os princípios de uma interação social com a natureza que mais evitariam a ocorrência de degradaçōes ambientais significativas? E haveriam expectativas sociais da natureza que pudessem ser qualificados de apropriadas?

\section{UM ESBOÇO DE ENFRENTAMENTO POSSÍVEL PARA A QUESTĀo}

Elaboração de um amplo painel associativo, no geral as relações dialéticas entre o percepto (a paisagem), seus índices (suas representações e transformações) e os juízos perceptivos estabelecidos, efetivem uma estratégia de percepção ambiental; de forma que a medida da desordem (entropia), ou seja, nonível de continuidade ehomogeneidade percebidos na escala (regional) de investigação, e da correlata dificuldade de estabelecimento dos sistemas de ordem anterior, possam ser detectados.

Para o enfrentamento destes fenômenos de representatividade, associatividade e interpretatividade, está previsto o desenvolvimento da seguinte sequiência de abordagem ${ }^{1}$, observando que este processo deverá sempre estar sob o controle da experiência, dada pela vivência do espaço em estudo:

\section{A Paisagem como Natureza}

O movimento romântico no séc. XVIII, principalmente na Inglaterra e outros países já envolvidos nas modernizações e avanços impostos pela industrialização, veio a se 
caracterizar como uma reação àquela visão estabelecida pelo elenco de crenças acumuladas ao longo da história ocidental, eminentemente antropocêntricos, e que passaram a ser postas em cheque com a revalorização do "natural" ou seja da visão de uma arcádiaperdida, do selvagem, dasplantase animais, como fontede prazerede valoresmorais.

Esta visão veio a ser muito impulsionada durante o séc. XIX, com o desenvolvimento dasciências naturais, com o avançodoconhecimentodesvendando os ciclose processos naturais, revelando toda uma intrincada teia de relações que sustentam a vida neste planeta, dando origem à compreensão da:

a. Paisagem como um sistema, em que integrada pelo conceito dos sistemas espaciais ou ecossistemas, passou a ser "visivel" ou ao menos os seus sintomas, uma série de processos subjacentes que se encarregam de circular a energia e a matéria, criando e refazendo continuamente, em busca de um clímax de equilíbrio dinâmico, numa evolução contínua.

Com o crescimento da capacidade tecnológica e de amplitude das intervenções humanas, principalmente ao longo deste século, veio a se ter a percepção da:

b.Paisagem como um problema, ou seja, do índice da degradaçãodos sistemas naturais, sob o impacto ambiental das intervenções humanas, medidas pelos níveis de poluição do solo, água e ar; dos desmatamentos e processos erosivos, da desertificação, das disfunções dos grandes aglomerados urbano-industriais, etc., de todas estas metástases expostas sem pudor na paisagem.

\section{A Paisagem como Artefato}

Uma outra percepção que muito contribui para a atual forma de comportamento da humanidade em relação ao mundo natural parte da consideração de que todo o conjunto de matérias-primas existentes no planeta está em uso, ou potencialmente, com o objetivo de ser transformada e usada pelo homem como uma alavanca para seu desenvolvimento; e que deste modo a sujeição da natureza aos seus interesses imediatistas ou não é um dado inquestionável, o que leva à avaliação da:

a. Paisagem como riqueza, ou seja, o valor de uso que o solo propicia, com todas as infraesıruturações existentes, permite observar a paisagem como um valor qualificado na moeda corrente do dia, sujeita a oscilações, mas ainda imprescindível.

Esta instância econômica do espaço permite trabalhar com os aspectos de localização, independentemente da situação geográfica, sendo que estas localizações podem ser 
definidas por relações transnacionais, medializadas pelos avanços tecnológicos, mas o que esta dedução possibilita é a compreensão da:

b. Paisagem como ideologia, como a fixadorn das crenças, de fossilizadora dos hábitos e das atitudes, da resistência à substituição do velho pelo novo. Esta característica da paisagem permite deduzir o processo histórico que teve seu desenvolvimento neste espaço, pois o conjunto de objetos e processos de transformação e produção se encontram indelevelmente gravados na somatória que a configuração atual da paisagem sintetiza. Algumas situações podem estar tão modificadas que os estágios anteriores não se revelam tão facilmente, sendo necessário o uso de inferências para, numa espécie de arqueologia da paisagem, ir revelando as camadas que escondem a gênese da imagem atual.

\section{A Paisagem como Projeto}

Os elementos de composição fornecidos pela paisagem podem ser vistos de duas formas:

a. A paisagem como lugar, a especificidade e unicidade de uma determinada porção do espaço pode ser conferida pela relação de vivência dada pelo homem, a lotalidade das sensações percebidas pelos nossos órgãos sensoriais, mediadas pelo nosso repertório pessoal, ou mesmo coletivo, permile-nos estabelecer relações emocionais bastante intensas, e conferir uma determinada "cor" local, assim temos na diversidade destas situações, na sua conservação e valorização, um grande clemento de apoio para o projeto, que também pode ver:

b. A paisagem como estética, "Measurement in the landscape is not a matter of meters and feet, but of rolling contours, spaced verticals, soft canopies and distinct edges. The measurement of inhabitation are not just elements of shelter, but recurring units of construction that define a human rhythm through the place, making the presence of self" .

Esıa "qualidade artística" conferida à paisagem, lanto na sua leitura, quanto nas proposições projetuais podeser vista como uma revalorização dos valores de Constable, e outros pintores paisagistas ingleses românticos. Mas além da busca da forma mais "pura" para a paisagem esłá a abstração totalizadora, que ao se trabalhar com os elementos de linguagem das artes plásticas: cor, texlura, massa, linha, posição, simetria, balançoe tensão; pode ser vislumbrada, e assim, ajudar a complelar, com mais este juízo perceptivo, este painel de associações aqui delineado; e ao mesmo tempo, lançar as formas possíveis, capazes de otimizar a evolução espacial, atendendo os requisitos da função projetual na paisagem. 


\section{NOTAS}

(1) Baseado em MEDNGI, D. W., L. A., 1976.

(2) Donlyn Lyndon, Places, v. 4, n . 4, p. 88.

\section{BIBLIOGRAFIA}

APPLETON, J. The experience of landscape. London, 1975.

ARNHEIM, R. Arte e percep̧̧̄o visual. EDUSP, 1980.

BERGER, J. Guidelines, for landscape synthesis: some directions old and new. Landscape and Uiban Planning, n. 14, 1987.

BERRY, B. Mudanças deliberadas nos sistemas espaciais. Sảo Paulo: EGEOGUSP. 1975. BIRD, E. The social constructions of nature. Environmental Review, v. 11, n. 4, 1987.

BROWN, T. et al. Aesthetics and manegement.: Bridging the gap. Landscape and Urban Planning, n. 13, p. 1-10, 1986.

CATS BAROL, W. Evaluating landscape acsthetics: a multi attribute utility approach. Landscape and Urban Planning, n. 14, p. 563-480, 1987.

GARRET, E. The landscape we see. New York: Mc Graw Hill, 1969.

KOPPES,C. Eticiency/Equity/Esthetics: towards a reinterpretation of American Conservation. Environmental Review, Summer, p. 127-146, 1987.

KOSIK, K. A Dialética do concreto.

LYNCH, Kevin. A imagem da cidade. São Paulo: Martins Fontes, 1982.

MEINIG, D. W. The Beholding Eye: Ten versions of the same scene.Landscape Architecture, jan. 1976.

NIEMANN, E. Polyfunctional landscape evaluation: aims and methods. Landscape and Urban Planning, n. 13, p. 135-151, 1986.

OPIE, J. Renaissance origins of the environmental crisis. Environmental Review, Spring, p. 2-17, 1987.

PIERCE. Collected papers. Cambrindge: Harvard Press, v. 7, n. 5, 1966.

RAPOPORT, Amos. Aspectos humanos de la forma urbana. Barcelona, v. 6, 1978.

SESSIONS, G. The deep ecology movement: a review. Environmental Review, Summer, p. 105-175, 1987.

SANTOS, M. Espaşo e método. São Paulo: Nobel, 1985.

THOMAS, Keith. O homem e mundo natural. São Paulo: Cia. das Letras, 1988. 